\section{METHODS OF TESTING THE MECHANICAL PROPERTIES OF ADDITIVELY MANUFACTURED COMPONENTS}

TATANA HRBACKOVA ${ }^{1}$, THOMAS SIMSON ${ }^{2}$, JURGEN KOCH
GERHARD WOLF $^{3}$, MARTINA KOUKOLIKOVA $^{1}$,
KATERINA MERTOVA

${ }^{1}$ COMTES FHT a.s., Prumyslova 995, 33441 Dobrany, Czech Republic

${ }^{2}$ Ostbayerische Technische Hochschule Amberg-Weiden, Germany

${ }^{3}$ Fraunhofer-Institut für Umwelt-, Sicherheits- und Energietechnik UMSICHT, Germany

DOI : 10.17973/MMSJ.2019_06_2018114 e-mail: thrbackova@comtesfht.cz

One of the main advantages of additive manufacturing is the possibility of custom-made machine parts. Additive manufacturing enables the production of components with fine details that would be difficult to manufacture with conventional production. This, however, brings some difficulty in the case of the acquisition of conventional test specimens that might exceed the size of the product. Mechanical properties of the tested materials via standard and microtensile test specimens were analysed. The materials AlSi10Mg and MS1 in as-built (AB) and heat treated (HT) conditions were produced by laser powder bed fusion. The aim of the research is to observe the influence of parameters (sample size, direction of testing) on the resulting mechanical properties. Mechanical testing is supported by metallographic and fractographic analysis.

KEYWORDS

additive manufacturing, tensile tests, micro-tensile tests MS1, ALSIIOMG

\section{INTRODUCTION}

In recent years additive manufacturing ( $A M)$ techniques have been introduced as a method to produce complex metallic parts. Additive manufacturing enables the production of detailed and complex components that cannot be produced by conventional technologies. First, a computer-aided design (CAD) file of the desired part needs to be created. Then, the CAD file will be converted into layers with specific thickness. Finally, an AM machine will fabricate the part layer by layer. All AM machines need a source of energy to fabricate the cross section of each layer. There are a variety of energy sources, including those based on laser, electron beam and ultrasonic [Bian 2018]. Mechanical properties of these components are usually tested on fabricated samples, because samples cannot be usually extracted from fabricated component by AM technology, for their prescribed size for testing. Solution may be using of sub-size samples for mechanical testing (M-TT micro-tensile tests) extracted from any part of the component [Dzugan 2017], [Dzugan 2018]. The samples used for the experiment were fabricated by laser powder bed fusion. The aim of the research is to observe the influence of parameters of different heat treatment conditions on resulting mechanical properties and comparison of the standard tensile tests and micro-tensile tests from sub-size samples, both fabricated by AM technology.

\section{EXPERIMENTAL PROCEDURE}

Materials that were tested in different heat treatment conditions are maraging steel MS1 and aluminium alloy AlSi10Mg. These two materials were selected from the most commonly used alloys in AM sector. Samples of tested materials were heat treated (HT) or they remained in as-built state (AB). Table 1 summarizes the heat treatment condition of the samples.

\begin{tabular}{|l|l|}
\hline Sample & Heat treatment condition \\
\hline MS1-AB & No heat treatment \\
\hline MS1-HT & $\begin{array}{l}\text { Solution annealing } 850^{\circ} \mathrm{C} \text { for } 1 \text { hour, ageing } \\
\text { temperature } 480^{\circ} \mathrm{C} \text { for } 3 \text { hours, air cooling }\end{array}$ \\
\hline AlSi10Mg-AB & No heat treatment \\
\hline AlSi10Mg-HT & Stress relieve $300^{\circ} \mathrm{C}$ for 2 hours
\end{tabular}

Table 1. Heat treatment condition of the analyzed samples

Standard tensile tests (TT) were carried out on fabricated samples in horizontal direction $\left(0^{\circ}\right)$ and micro-tensile tests (M$\mathrm{TT}$ ) were carried out on samples extracted from TT samples in three directions (horizontal direction- $0^{\circ}, 45^{\circ}$ and building direction- $\left.90^{\circ}\right)$. Ostbayerische Technische Hochschule AmbergWeiden carried out standard tensile tests of as-built $(A B)$ and heat-treated $(\mathrm{HT})$ samples. Three $A B$ samples and three $H T$ samples of each material extracted in horizontal direction (axis $X$ in Figure 1) were tested. The dimension of the TT samples is shown in Figure 2.

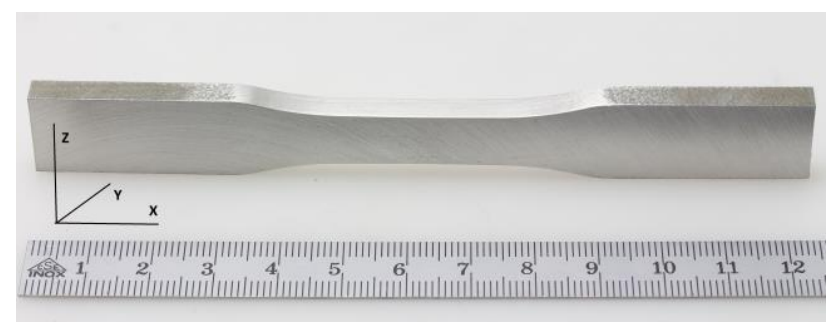

Figure 1. Schematic of TT samples position during fabrication process

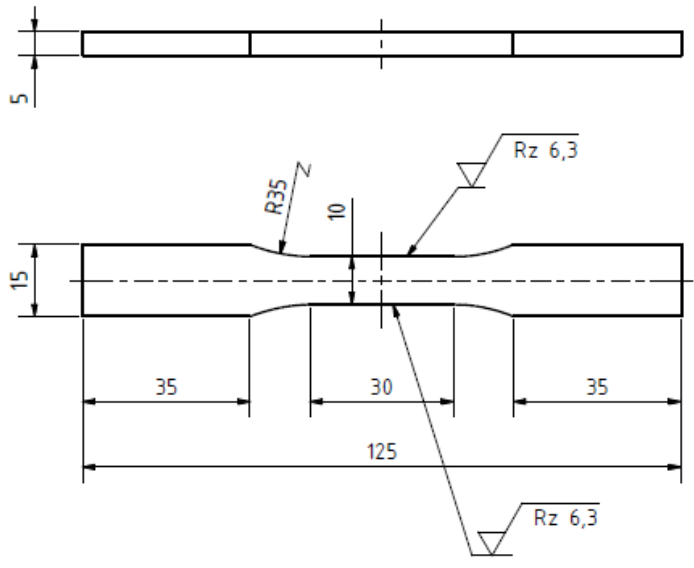

Figure 2. Detailed dimensions of TT samples 
The summarized values of the tensile test stress-strain characteristics (yield stress YS, tensile strength UTS and elongation EL) are given in Table 2.

Tensile test method using miniaturized tensile specimens was developed in COMTES FHT [Dzugan 2017], [Dzugan 2018].

\begin{tabular}{|c|c|c|c|c|}
\hline Sample & Results & $\begin{array}{l}\text { YS } \\
\text { [MPA] }\end{array}$ & $\begin{array}{l}\text { UTS } \\
\text { [MPA] }\end{array}$ & $\begin{array}{l}\text { EI } \\
\text { [\%] }\end{array}$ \\
\hline \multirow[t]{2}{*}{ MS1-AB } & Mean & 1061 & 1179 & 9,3 \\
\hline & S. Dev. & 7 & 5 & 0,1 \\
\hline \multirow[t]{2}{*}{ MS1-HT } & Mean & 1826 & 1897 & 5,2 \\
\hline & S. Dev. & 17 & 5 & 0,1 \\
\hline \multirow{2}{*}{$\begin{array}{l}\text { AlSi10Mg- } \\
\text { AB }\end{array}$} & Mean & 203 & 283 & 2,5 \\
\hline & S. Dev. & 8 & 42 & 1,5 \\
\hline \multirow{2}{*}{$\begin{array}{l}\text { AlSi10Mg- } \\
\text { HT }\end{array}$} & Mean & 149 & 231 & 3,4 \\
\hline & S. Dev. & 2 & 16 & 1,6 \\
\hline
\end{tabular}

Table 2. Mean values from all standard tensile test results

The basis of the test comes from the ISO 6892-1 standard at ambient temperature. However, as these standards do not consider the testing of miniature bodies, the procedure with the internal regulation has been developed and accredited. Tests were carried out on a testing machine Labcontrol with the loading capacity of $5 \mathrm{kN}$. Deformation was measured by means of optical extensometer working based on a Digital Image Correlation technique (DIC). Example of DIC can be seen in Figure 3. As the optical extensometer using one camera, the MERCURY RT (real-time tracking) system was used.

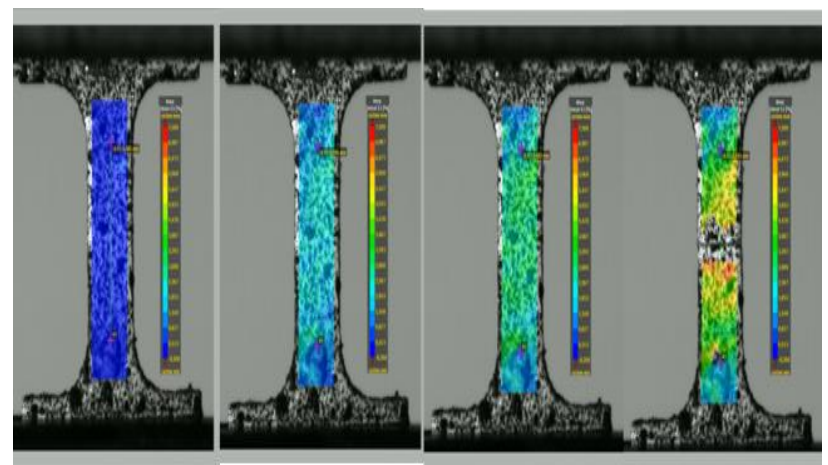

Figure 3 Example of DIC strain measurement for M-TT

Micro-tensile tests were carried out on samples of the maraging steel MS1 and the aluminium alloy AlSi10Mg in a different heat treatment conditions. Nine specimens were extracted from unaffected locations of all TT samples after tensile tests in different orientation: horizontal direction $\left(0^{\circ}\right)$, $45^{\circ}$ and building direction $\left(90^{\circ}\right)$ (Figure 4). In total more than hundred micro-tensile test specimens were tested. Geometry of the M-TT samples is shown in Figure 5.

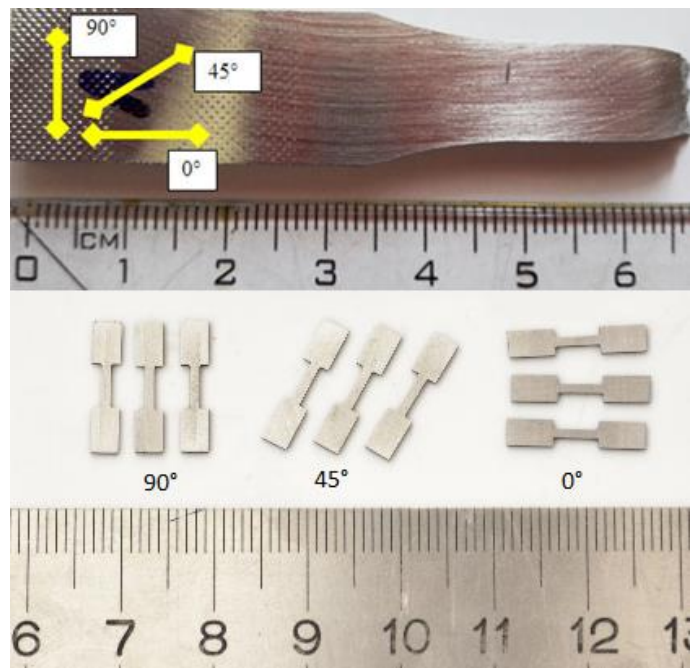

Figure 4. Extraction of the M-TT samples from TT samples in different directions
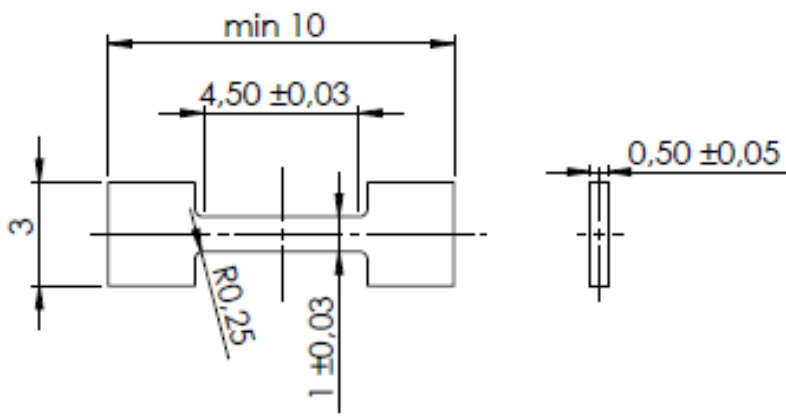

Figure 5. Geometry of M-TT specimens

Average values of yield stress (YS), ultimate tensile strength (UTS), elongation (EI) for maraging steel MS1 and aluminium alloy AlSi10Mg are summarized in Table 3 and Table 4.

\begin{tabular}{|c|c|c|c|c|c|}
\hline Sample & $\begin{array}{l}\text { Orie } \\
\text { ntat } \\
\text { ion }\end{array}$ & Results & $\begin{array}{l}\text { YS } \\
\text { [MPA] }\end{array}$ & $\begin{array}{l}\text { UTS } \\
\text { [MPA] }\end{array}$ & $\begin{array}{l}\text { EI } \\
\text { [\%] }\end{array}$ \\
\hline \multirow{6}{*}{ MS1-AB } & \multirow{2}{*}{$0^{\circ}$} & Mean e & 1004 & 1147 & 11 \\
\hline & & S. Dev. & 5 & 9 & 3 \\
\hline & \multirow{2}{*}{$45^{\circ}$} & Mean & 984 & 1074 & 4 \\
\hline & & S. Dev. & 41 & 72 & 1 \\
\hline & \multirow{2}{*}{$90^{\circ}$} & Mean e & 925 & 930 & 2 \\
\hline & & S.Dev. & 114 & 116 & 1 \\
\hline \multirow{6}{*}{ MS1-HT } & \multirow{2}{*}{$0^{\circ}$} & Mean & 1750 & 1831 & 5,5 \\
\hline & & S. Dev. & 4 & 11 & 1,4 \\
\hline & \multirow{2}{*}{$45^{\circ}$} & Mean & 1730 & 1763 & 1,5 \\
\hline & & S. Dev. & 8 & 46 & 1 \\
\hline & \multirow{2}{*}{$90^{\circ}$} & Mean & 1654 & 1706 & 1 \\
\hline & & S.Dev. & 77 & 51 & 0 \\
\hline
\end{tabular}

Table 3. Mean values from maraging steel M-TT tensile test results 


\begin{tabular}{|c|c|c|c|c|c|}
\hline Sample & $\begin{array}{l}\text { Orie } \\
\text { ntat } \\
\text { ion }\end{array}$ & Results & $\begin{array}{l}\text { YS } \\
\text { [MPA] }\end{array}$ & $\begin{array}{l}\text { UTS } \\
\text { [MPA] }\end{array}$ & $\begin{array}{l}\text { El } \\
\text { [\%] }\end{array}$ \\
\hline \multirow{6}{*}{$\begin{array}{l}\text { AlSi10Mg- } \\
\text { AB }\end{array}$} & \multirow{2}{*}{$0^{\circ}$} & Mean & 203 & 286 & 2 \\
\hline & & S. Dev. & 2 & 10 & 0 \\
\hline & \multirow{2}{*}{$45^{\circ}$} & Mean & 197 & 282 & 2 \\
\hline & & S. Dev. & 13 & 18 & 1 \\
\hline & \multirow{2}{*}{$90^{\circ}$} & Mean & 195 & 275 & 1 \\
\hline & & S.Dev. & 16 & 23 & 0 \\
\hline \multirow{6}{*}{$\begin{array}{l}\text { AlSi10Mg- } \\
\text { HT }\end{array}$} & \multirow{2}{*}{$0^{\circ}$} & Mean & 172 & 242 & 7 \\
\hline & & S. Dev. & 7 & 11 & 1,1 \\
\hline & \multirow{2}{*}{$45^{\circ}$} & Mean & 168 & 243 & 5,5 \\
\hline & & S. Dev. & 8 & 6 & 1 \\
\hline & \multirow{2}{*}{$90^{\circ}$} & Mean & 171 & 239 & 4 \\
\hline & & S.Dev. & 9 & 7 & 1 \\
\hline
\end{tabular}

Table 4. Mean values from aluminium alloy AISi10Mg M-TT tensile test results

\subsection{Comparison of the results}

\subsubsection{Maraging steel}

Figure 6 to figure 11 show comparisons of the results of standard tensile tests (TT) carried out in horizontal direction and micro-tensile tests (M-TT) carried out in different directions of testing.

Graphs in Figure 6 and Figure 7 show, that the results of MS1 yield stress and ultimate tensile strength are comparable for all sizes and directions of testing. M-TT samples in horizontal direction exhibit slightly lower values as they are more sensitive to the material defects in the microstructure. The highest values of M-TT samples ultimate tensile strength and yield stress are in horizontal direction $\left(0^{\circ}\right)$. The lowest values exhibit samples in building direction $\left(90^{\circ}\right)$. Higher sensitivity to defects can be manifested also in higher scatter of measured M-TT samples values in as-built state, where the deviation of strengths in direction $45^{\circ}$ and particularly in building direction $\left(90^{\circ}\right)$ is significantly larger than for horizontal direction $\left(0^{\circ}\right)$. This phenomenon is much less pronounced after heat treatment of MS1, most likely by changing the microstructure and stress reduction after heat treatment.

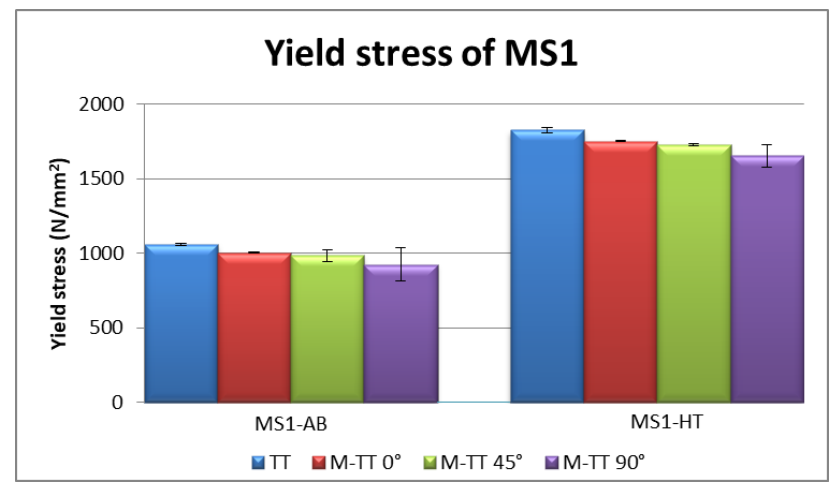

Figure 6. Comparison of the yield stress for MS1

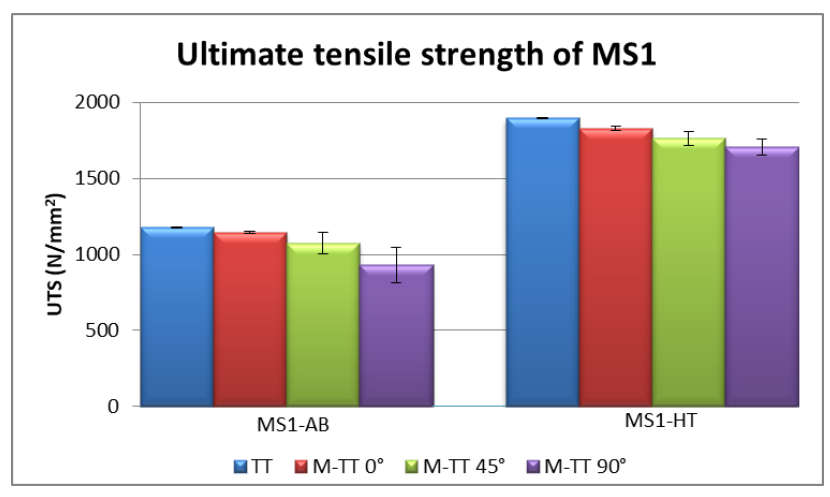

Figure 7. Comparison of the ultimate tensile strength for MS1

MS1 elongation varies with the direction of testing. For samples tested in horizontal direction $\left(0^{\circ}\right)$, the tensile loadings affect in the layers parallel to the $X$ direction, so the results in horizontal direction $\left(0^{\circ}\right)$ exhibit the highest values (Figure 8). Elongation decreased in the direction across the layers of samples fabricated by additive manufacturing.

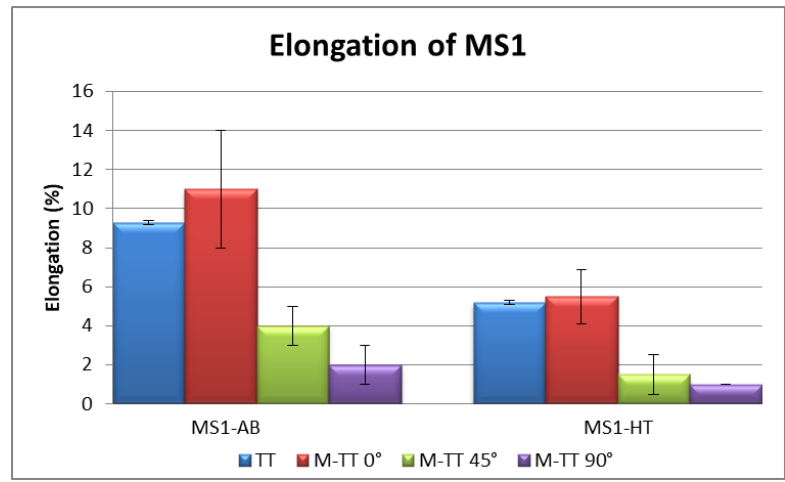

Figure 8. Comparison of the elongation of MS1

The lowest values of the mechanical properties exhibit samples in building direction $\left(90^{\circ}\right)$, which is attributed to more borderline porosity being formed in the z-oriented tensile samples, stress concentration effect caused by the loading direction being perpendicular to the orientation of the planar defects (lack of fusion), effect of texture and track and layer interfaces [Brandt 2017].

Comparison of the results for different samples size demonstrates that M-TT samples have slightly higher values.

\subsubsection{Aluminium alloy AlSi10Mg}

Graphs in Figure 9 and Figure 10 again demonstrate that the size and direction of testing had no apparent effect on yield stress and ultimate tensile strength.

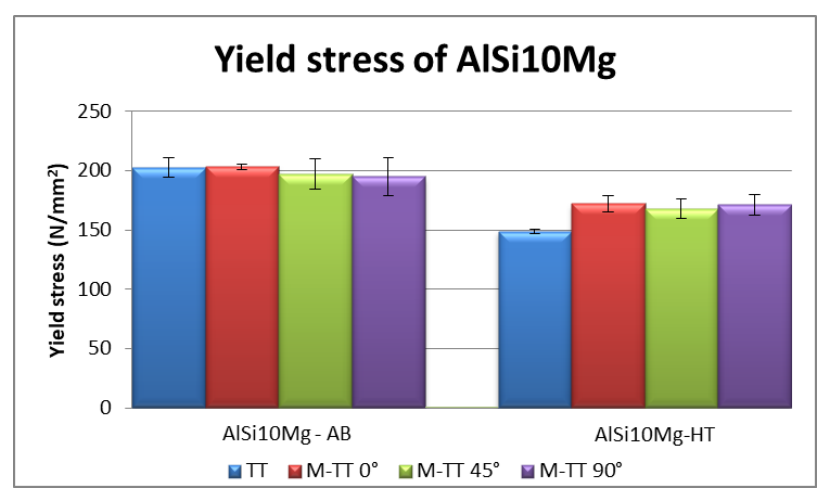

Figure 9. Comparison of the yield stress for AlSi10Mg 


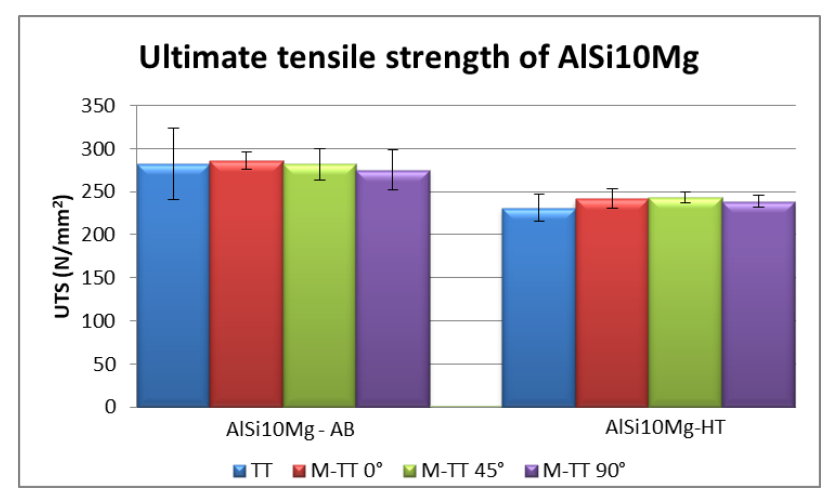

Figure 10. Comparison of the ultimate tensile strength for AISi10Mg

The elongation results of the aluminium alloy AlSi10Mg in the as-built state, shown in Figure 11, are comparable for all sizes and directions of testing. The lowest values exhibit again samples in building orientation $\left(90^{\circ}\right)$.

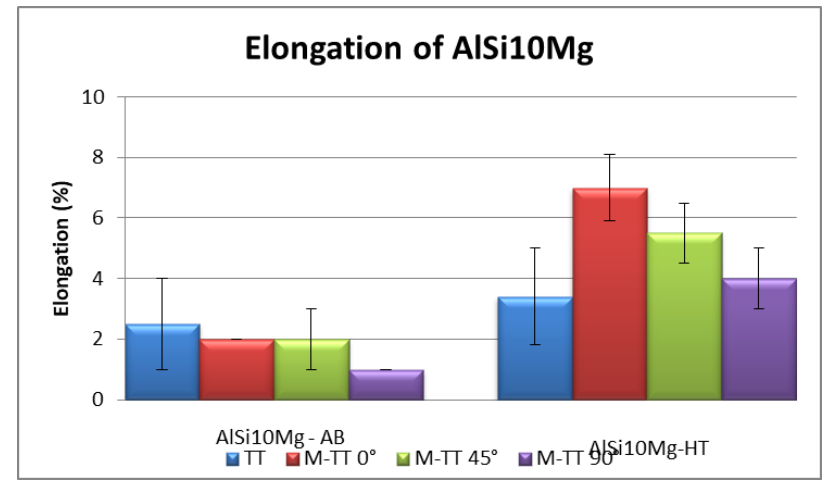

Figure 11. Comparison of the elongation for AlSi10Mg

This is because of the optimal density scanning strategy which causes more borderline porosity in the building direction. These pores make the samples in building direction more sensitive to crack initiation, compared to horizontal oriented tensile samples [Kempen 2012]. Elongation of the M-TT samples in the annealed state is higher in all testing directions in comparison to the standard tensile samples in the annealed state.

\subsection{Fractography}

After the TT and M-TT tensile tests, a fractographic analysis was performed on samples using the scanning electron microscopy (SEM). For all samples, a ductile fracture with typical dimple morphology was observed as documented in the Figure 12, where are seen examples of fractures in the as-built state. Defects such as lack of fusion and porosity are visible on the fracture surfaces.

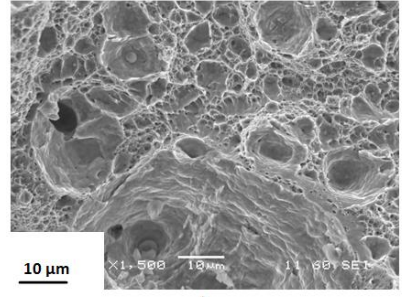

a)

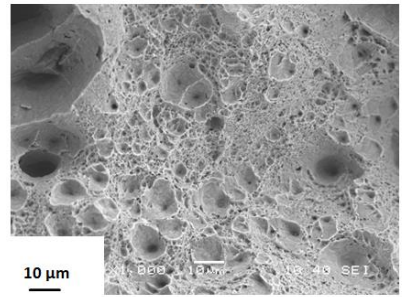

c)

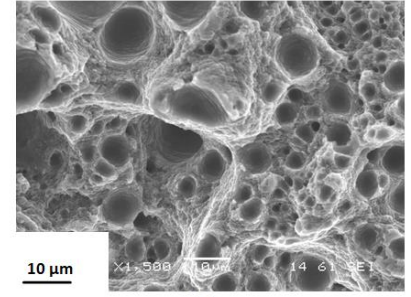

b)

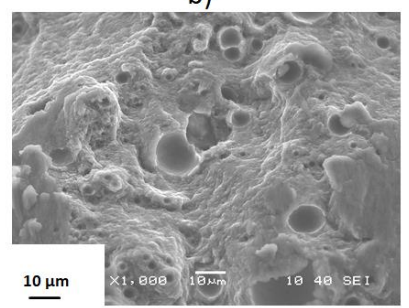

d)

Figure 12. SEM images of tensile fracture surfaces in as-built state a) TT sample of MS1, b) TT sample of AISi10Mg, c) M-TT sample of MS1, d) M-TT sample of AlSi10Mg

Figure 13 shows lack of fusion located on the fracture surface of the MS1 M-TT sample. Lack of fusion is caused if powder particles were not melted during the additive manufacturing process.

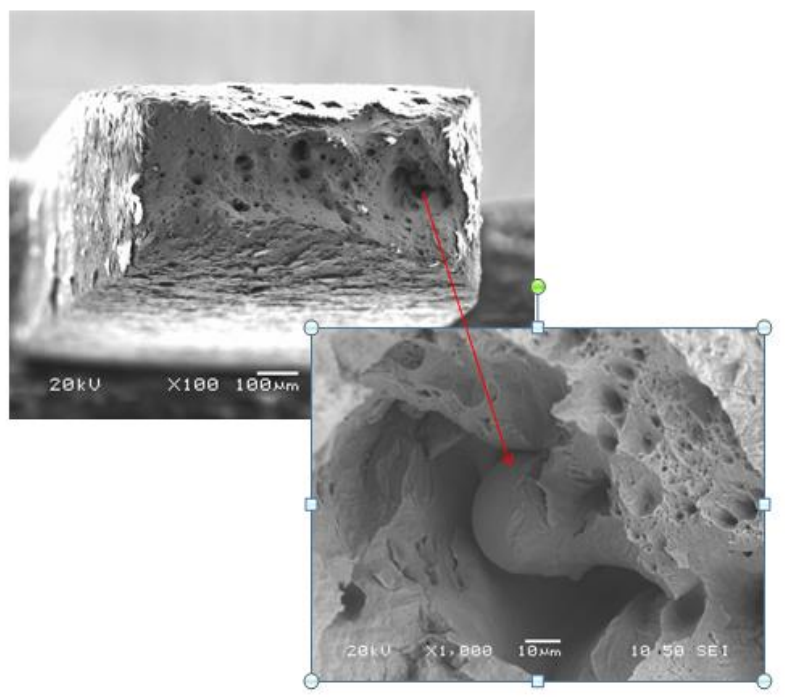

Figure 13. M-TT sample's fracture surface of maraging steel MS1 in asbuilt state with detail of material defect - lack of fusion (red arrow)

\subsection{Microstructure}

Microstructure analysis was performed in plane XZ (along the building axis). Samples underwent standard metallographic preparation consisted of grinding followed by polishing. The microstructure of the maraging steel was revealed by etching in Picral 4\%. Aluminium alloy AlSi10Mg was etched with Keller's reagent. The metallographic observation was performed by means of a light microscope.

Figure 14 documented the microstructure of the maraging steel MS1 and aluminium alloy AlSi10Mg. Images show the structures of untreated materials with semicircularly shaped melt pools along the $Z$ axis. After the heat treatment, the maraging steel MS1 melt pool borders disappeared, the melt pool borders of the AISi10Mg are less visible. 


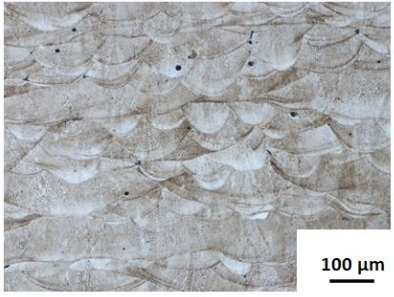

a)

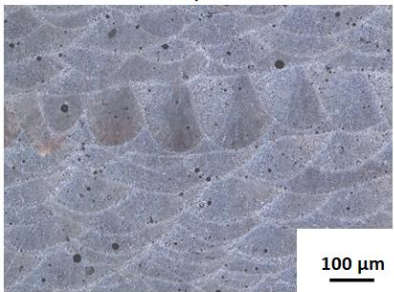

c)

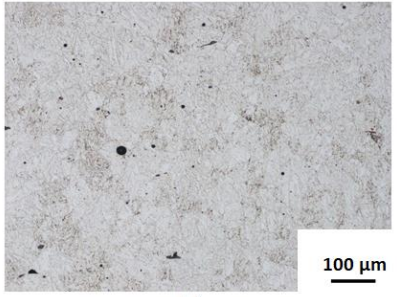

b)

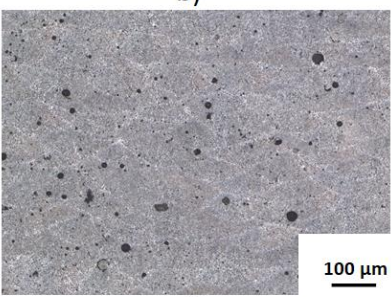

d)
Figure 14. Microstructure of samples in XZ plane a) MS1 in as-built state, b) MS1 in heat treated state, c) AlSi10Mg in as-built state, d) AlSi10 in heat treated state

\section{CONCLUSIONS}

In this study the influence of parameters on mechanical properties of maraging steel MS1 and aluminium alloy AlSi10Mg in different heat treatment conditions were observed and standard tensile tests were compared with micro-tensile tests. The samples size and direction of the testing showed no demonstrable effect on the values realized of the yield stress and ultimate tensile strength. The lowest values exhibit samples in building direction $\left(90^{\circ}\right)$. Elongation decreased in orientation $45^{\circ}$ and building direction, which is attributed to more borderline porosity being formed in the z-oriented tensile samples, stress concentration effect caused by the loading direction being perpendicular to the orientation of the planar defects (lack of fusion), effect of texture and track and layer interfaces. In case of samples with the building direction the lowest values of strength have been observed. Elongation of the M-TT samples in annealed state is higher in all testing directions in comparison to the annealed state of TT samples.

\section{Acknowledgement}

These results were created under the project entitled 3D COVER - Metallic materials in the process chain of additive manufacturing, Project No.: 185, financed by the ERDF.

\section{REFERENCES}

[Bian 2018] Bian, L, et. al. Laser-Based Additive Manufacturing of Metal Parts: modeling, optimization and control of mechanical properties. Boca Raton: Taylor \& Francis Group, 2018. ISBN 13:978-1-4987-3998-6

[Brandt 2017] Brandt, M. Laser Additive Manufacturing: Materials, Design, Technologies, and Applications. Elsevier Ltd. 2017. ISBN: 978-0-08-100434-0

[Dzugan 2017] Dzugan, J. et. al. Mechanical properties determination of AM components. February 2017. IOP Conf. Ser.: Mater. Sci. Eng. 179012019

[Dzugan 2018] Dzugan, J. et. al. Effects of thickness and orientation on the small scale fracture behaviour of additively manufactured Ti-6Al-4V. Materials Characterization, April 2018. https://doi.org/10.1016/j.matchar.2018.04.003

[Kempen 2012] Kempen, K. et. al. Mechaanical properties of AlSi10Mg produced by selective laser melting. Published by Elsevier B.V. Selection and/or review under responsibility of Bayerisches Laserzentrum GmbH: 2012. Physics Procedia 39 (439-446)

\section{CONTACT}

Bc. Tatana Hrbackova

COMTES FHT a.s., Materials analysis

Prumyslova 995, Dobrany, 344 41, Czech Republic

+420 377197 341, thrbackova@comtesfht.cz, www.comtesfht.cz 